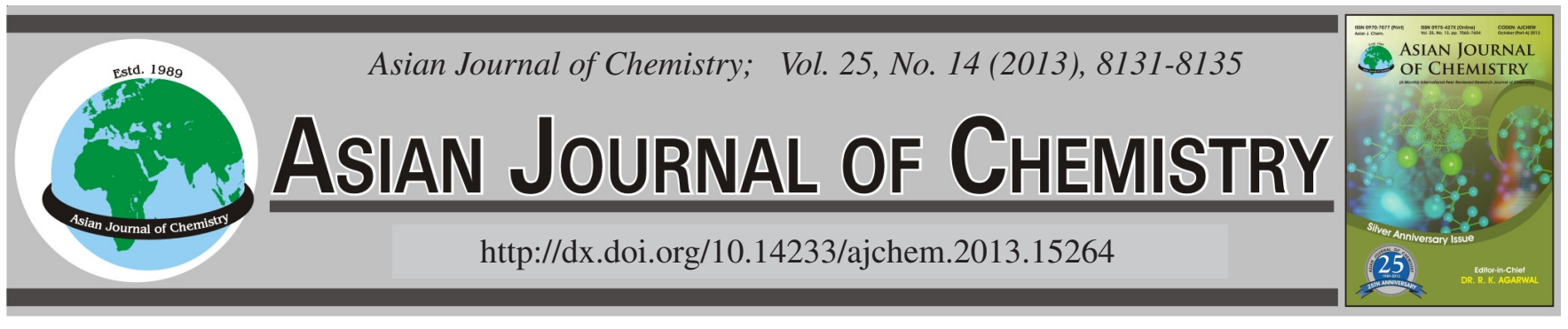

\title{
Spectroscopic Studies on the Interaction of Polydatin with Bovine Serum Albumin
}

\section{XIAOLI LiU ${ }^{1,2}$ and Hua Li ${ }^{3, *}$}

${ }^{1}$ College of Life Sciences, Northwest University, Xi'an, P.R. China

${ }^{2}$ College of Environmental Science and Engineering, Chang'an University, Xi'an, P.R. China

${ }^{3}$ Institute of Analytical Science, Northwest University, Xi'an, P.R. China

*Corresponding author: Tel: +86 29 88302635; E-mail: nwufxkx2012@126.com

\begin{abstract}
The interaction of polydatin with bovine serum albumin has been studied by spectroscopic methods including fluorescence, ultravioletvisible and Fourier transform infrared spectroscopy. The intrinsic fluorescence of bovine serum albumin is quenched in the presence of polydatin and the quenching mechanism is suggested as static quenching procedure. The thermodynamic parameters $\Delta \mathrm{H}$ and $\Delta \mathrm{S}$ are estimated to be $-49.92 \mathrm{~kJ} \mathrm{~mol}^{-1}$ and $-78.81 \mathrm{~J} \mathrm{~mol}^{-1} \mathrm{~K}^{-1}$, which indicates that the interaction of polydatin with bovine serum albumin is driven mainly by hydrogen bonds and van der Waals interactions. The number of binding sites of polydatin to bovine serum albumin is approximately equal to unity and the competitive experiments suggest that the binding site is probably located on site II of bovine serum albumin. The quantitative analysis of infrared spectra data shows that the binding stabilizes the $\alpha$-helix and $\beta$-sheet structure of bovine serum albumin at the cost of a loss in the $\beta$-turn structure.
\end{abstract}

Key Words: Polydatin, Bovine serum albumin, Fluorescence quenching, Infrared spectroscopy.

\section{INTRODUCTION}

Serum albumins are the most abundant proteins in blood plasma, many drugs bind reversibly to serum albumins and are transported in blood. The binding ability of drug-albumin may have a significant impact on distribution, free concentration and metabolism of the drug ${ }^{1,2}$. Thus, it is important and necessary to study the interaction of drugs with serum albumins at molecular level. Among the serum albumins, bovine serum albumin (BSA) is an appropriate protein model for studying the interaction between serum albumins and drugs because of its medicinal importance, unusual ligand-binding properties, availability, low cost and structural homology with human serum albumin (HSA) ${ }^{3}$. The bovine serum albumin molecule is made up of three homologous domains which are divided into nine loops by 17 disulfide bonds.

Polydatin, 3,4',5-trihydroxystilbene-3- $\beta$-mono-D-glucoside, is one of the effective ingredients extracted from Poligonum cuspidatum Sieb. et Zucc. It can be used to enhance microcirculation, protect myocardium and inhibit the aggregation of platelets ${ }^{4,5}$. It also can prevent indotoxin shock, resist superoxidation of lipid, lower lipid and control cough, asthma and pathogen ${ }^{6,7}$. It may be a valuable drug in clinical application. The molecular structure of polydatin is provided in Fig. 1. So far, most researches are focusing on the pharmacological activities of polydatin, little has been done on the interaction of polydatin

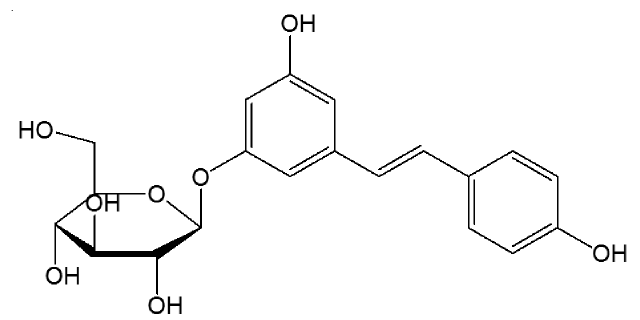

Fig. 1. Molecular structure of polydatin

with serum albumin. In this work, the interaction of polydatin with bovine serum albumin has been studied under imitated physiological conditions by spectroscopic methods. Fluorescence and UV-VIS spectroscopy were employed to understand the quenching mechanism of polydatin-bovine serum albumin binding. The binding constants, number of binding sites, thermodynamic parameters and binding distance have been calculated and the binding site of polydatin on bovine serum albumin was identified. FTIR spectroscopy was used for demonstrating the conformational changes of bovine serum albumin and the changes of main secondary structure were analyzed quantitatively.

\section{EXPERIMENTAL}

Polydatin was obtained from Xi' an Sino-Herb Biotechnology Company (Xi' an, China). Bovine serum albumin was purchased 
from Huamei Bioengineering Company (Shanghai, China). The polydatin stock solution $\left(1.0 \times 10^{-3} \mathrm{~mol} \mathrm{~L}^{-1}\right)$ was prepared in ethanol-water solution $(1: 1, \mathrm{v} / \mathrm{v})$. The bovine serum albumin stock solution $\left(1.0 \times 10^{-4} \mathrm{~mol} \mathrm{~L}^{-1}\right)$ was prepared in $\mathrm{pH} 7.4$ Tris-HCl buffer solution $\left(0.05 \mathrm{~mol} \mathrm{~L}^{-1}\right)$. Both of the stock solutions were stored at $0-4{ }^{\circ} \mathrm{C}$ prior to use. All other reagents were analytical-reagent grade and double distilled water was used throughout.

Methods: The fluorescence experiments were performed on an F-4500 fluorescence spectrophotometer (Hitachi). The concentrations of bovine serum albumin was constant at $3 \times$ $10^{-7} \mathrm{~mol} \mathrm{~L}^{-1}$ and the concentrations of polydatin were ranged from $0-2.4 \times 10^{-6} \mathrm{~mol} \mathrm{~L}^{-1}$. The fluorescence emission spectra were measured at different temperatures (292, 297 and $302 \mathrm{~K}$ ) in the wave-length range of $300-500 \mathrm{~nm}$ with exciting wavelength of $280 \mathrm{~nm}$.

The UV-visible absorption experiments were performed on a UV-2450 spectrophotometer (Shimadzu, Japan). The absorption spectra of polydatin solution, bovine serum albumin solution and polydatin-bovine serum albumin solution were measured in the range $200-500 \mathrm{~nm}$, respectively.

The displacement experiments were performed using three different site probes viz., digitoxin, flufenamic acid and phenylbutazone for site I, II and III, respectively. The concentrations of bovine serum albumin and site probes were constant at $3 \times$ $10^{-7}$ and $2 \times 10^{-7} \mathrm{~mol} \mathrm{~L}^{-1}$ and appropriate amount polydatin was added to the bovine serum albumin-probe systems. The fluorescence emission spectra were recorded with exciting wavelength of $280 \mathrm{~nm}$.

FTIR spectra were measured on a Vertex 70 FTIR spectrometer (Bruker optics, Germany). The FTIR spectra of bovine serum albumin solution, Tris- $\mathrm{HCl}$ buffer solution, bovine serum albumin-polydatin solution and polydatin solution were recorded via the attenuated total reflection method under the same conditions.

\section{RESULTS AND DISCUSSION}

Fluorescence quenching mechanism: The interaction of polydatin with bovine serum albumin was evaluated by monitoring the intrinsic fluorescence intensity change of bovine serum albumin in the presence of polydatin. The fluorescence emission spectra of bovine serum albumin in the presence of different concentrations of polydatin are shown in Fig. 2. It shows that bovine serum albumin has a strong fluorescence emission peak at about $347 \mathrm{~nm}$ after being excited with an exciting wavelength of $280 \mathrm{~nm}$ and the addition of polydatin results in a significant reduction in the fluorescence intensity with a slight red shift of maximum emission wavelength. It indicates that polydatin interacts with bovine serum albumin and quenches its intrinsic fluorescence and the microenvironment around the chromophore of bovine serum albumin is changed.

It is known that there are two quenching mechanisms involved in quenching process, i.e., dynamic quenching and static quenching. For dynamic quenching, the maximum scatter collision quenching constant of various quenchers with the biopolymers is $2.0 \times 10^{10} \mathrm{~L} \mathrm{~mol}^{-1} \mathrm{~s}^{-1}$. In addition, the values of quenching constant decrease with increasing temperature for

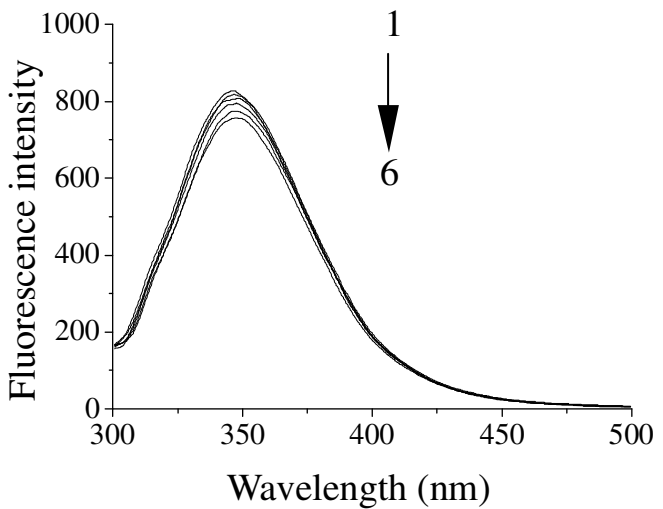

Fig. 2. Fluorescence quenching spectra of bovine serum albumin-polydatin system. (1-6): $\mathrm{C}_{\mathrm{BSA}}=3.0 \times 10^{-7} \mathrm{~mol} \mathrm{~L}^{-1}, \mathrm{C}_{\text {polydatin }}=0,3,6,12,18,24$ $\left(\times 10^{-7} \mathrm{~mol} \mathrm{~L}^{-1}\right)$, respectively; $\mathrm{T}=302 \mathrm{~K}$

static quenching and the reverse result for dynamic quenching ${ }^{8}$. To further clarify the quenching mechanism of polydatin on bovine serum albumin, fluorescence quenching data are analyzed by the Stern-Volmer equation?

$$
\frac{\mathrm{F}_{0}}{\mathrm{~F}}=1+\mathrm{K}_{\mathrm{q}} \tau_{0}[\mathrm{Q}]=1+\mathrm{K}_{\mathrm{SV}}[\mathrm{Q}]
$$

where $\mathrm{F}_{0}$ and $\mathrm{F}$ are the fluorescence intensities in the absence and presence of quencher, $\mathrm{K}_{\mathrm{q}}$ is the quenching rate constant of the biomolecule, $\mathrm{K}_{\mathrm{Sv}}$ is the Stern-Volmer quenching constant, $\tau_{0}$ is the average lifetime of the biomolecule in the absence of quencher which equals to $10^{-8} \mathrm{~s}$ and [Q] is the concentration of quencher ${ }^{10}$. Within certain concentration, the curve of $F_{0} / F$ versus [Q] would be linear if the quenching type is single static or dynamic process. The Stern-Volmer curves of polydatin with bovine serum albumin at three different temperatures are shown in Fig. 3, they exhibit good linear relationship within the investigated concentration, so the value of $\mathrm{K}_{\mathrm{q}}$ and $\mathrm{K}_{\mathrm{SV}}$ can be determined from the slope of regression curve of $\mathrm{F}_{0} / \mathrm{F}$ versus [Q] and the results are listed in Table-1. Table-1 showed that the values of $\mathrm{K}_{\mathrm{q}}$ is much greater than $2.0 \times 10^{10} \mathrm{~L} \mathrm{~mol}^{-1} \mathrm{~s}^{-1}$ and $\mathrm{K}_{\mathrm{SV}}$ decrease with the increasing of temperature, which indicates that the quenching mechanism of bovine serum albumin-polydatin interaction is initiated by static quenching. The results are also confirmed by UV-visible experiments as shown in Fig. 4. It is apparently observed that the UV-visible absorption spectrum of bovine serum albumin and the difference absorption spectrum between bovine serum albuminpolydatin and polydatin at the same concentration can not be superposed, the absorbance band intensity of bovine serum albumin at $280 \mathrm{~nm}$ decreases and the peak position shows a slight shift, which suggest the formation of bovine serum albumin-polydatin complex.

Binding constant and number of binding sites: For static quenching interaction, when small molecules bind independently to a set of equivalent sites on a macromolecule, the binding constant $\left(\mathrm{K}_{\mathrm{b}}\right)$ and the number of binding sites $(\mathrm{n})$ can be obtained from the double logarithm regression curve of $\log \left[\left(\mathrm{F}_{0}-\mathrm{F}\right) / \mathrm{F}\right]$ versus $\log [\mathrm{Q}]$ based on eqn. $2^{11}$. The corresponding calculated results are listed in Table-2.

$$
\log \left[\frac{\left(\mathrm{F}_{0}-\mathrm{F}\right)}{\mathrm{F}}\right]=\log \mathrm{K}_{\mathrm{b}}+\mathrm{n} \log [\mathrm{Q}]
$$




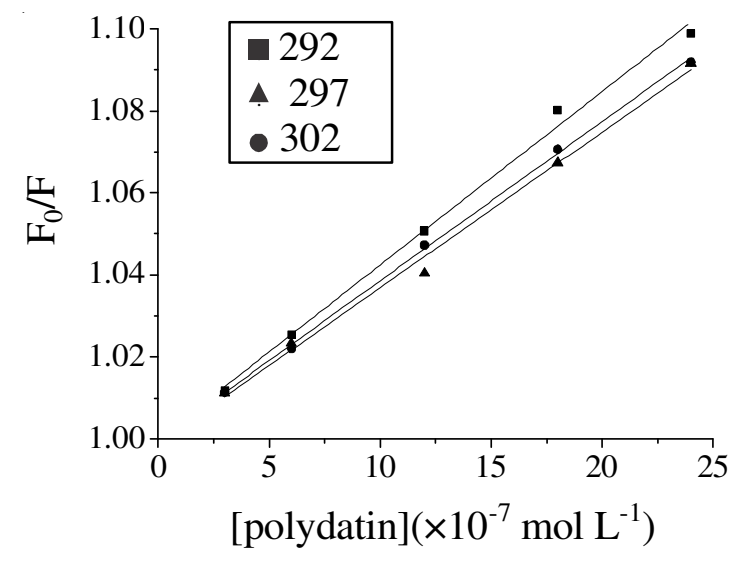

Fig. 3. Stern-Volmer plots at different temperatures

\begin{tabular}{cccc}
\multicolumn{5}{c}{ TABLE-1 } \\
STERN-VOLMER QUENCHING CONSTANT \\
AND BIMOLECULAR QUENCHING CONSTANT \\
AT DIFFERENT TEMPERATURES \\
\hline $\mathrm{T}(\mathrm{K})$ & $\mathrm{K}_{\mathrm{sv}}\left(\mathrm{L} \mathrm{mol}^{-1}\right)$ & $\mathrm{K}_{\mathrm{q}}\left(\mathrm{L} \mathrm{mol}^{-1} \mathrm{~s}^{-1}\right)$ & $\mathrm{R}^{\mathrm{a}}$ \\
\hline 292 & $4.23 \times 10^{4}$ & $4.23 \times 10^{12}$ & 0.9976 \\
297 & $3.88 \times 10^{4}$ & $3.88 \times 10^{12}$ & 0.9995 \\
302 & $3.79 \times 10^{4}$ & $3.79 \times 10^{12}$ & 0.9973 \\
\hline${ }^{a}$ Correlation coefficient. & &
\end{tabular}

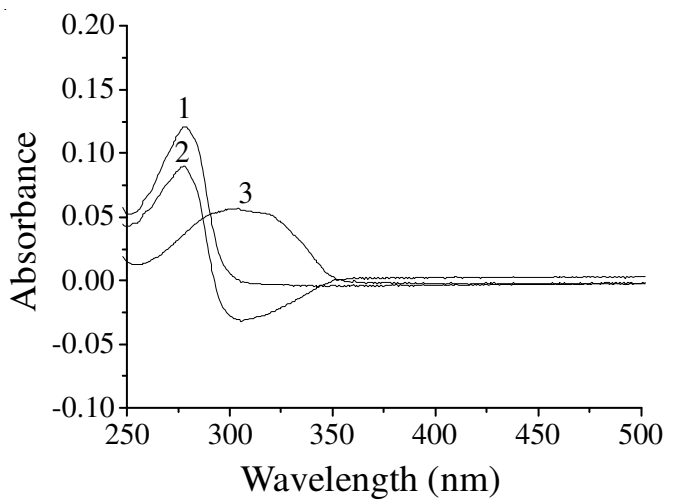

Fig. 4. UV-visible absorption spectra of bovine serum albumin (1), polydatin (2) and the difference spectrum between polydatin-bovine serum albumin (1:1) and polydatin (3). $\mathrm{C}_{\mathrm{BSA}}=\mathrm{C}_{\text {polydatin }}=3.0 \times 10^{-5}$ $\mathrm{mol} \mathrm{L}-1, \mathrm{~T}=298 \mathrm{~K}, \mathrm{pH}=7.4$

\begin{tabular}{cccccc}
\multicolumn{7}{c}{ TABLE-2 } \\
\multicolumn{5}{c}{ BINDING CONSTANTS AND THERMODYNAMIC } \\
PARAMETERS OF POLYDATIN-BSA INTERACTION \\
AT DIFFERENT TEMPERATURES \\
\hline $\mathrm{T}$ \\
$(\mathrm{K})$ & $\begin{array}{c}\mathrm{K}_{\mathrm{b}} \\
\left(\mathrm{L} \mathrm{mol}^{-1}\right)\end{array}$ & $\mathrm{n}$ & $\begin{array}{c}\Delta \mathrm{H} \\
\left(\mathrm{kJ} \mathrm{mol}^{-1}\right)\end{array}$ & $\begin{array}{c}\Delta \mathrm{S} \\
\left(\mathrm{J} \mathrm{mol}^{-1} \mathrm{~K}^{-1)}\right.\end{array}$ & $\begin{array}{c}\Delta \mathrm{G} \\
\left(\mathrm{kJ} \mathrm{mol}^{-1}\right)\end{array}$ \\
\hline 292 & $6.38 \times 10^{4}$ & 1.03 & & & -26.91 \\
297 & $4.80 \times 10^{4}$ & 1.02 & -49.92 & -78.81 & -26.52 \\
302 & $3.23 \times 10^{4}$ & 0.99 & & & -26.12 \\
\hline
\end{tabular}

It is found that the values of $\mathrm{K}_{\mathrm{b}}$ decrease with the increasing of temperature and $n$ approximately equal to 1 , indicating that the stability of polydatin-bovine serum albumin complex reduces with the temperature rising and there is one independent class of binding sites in bovine serum albumin for polydatin.

Thermodynamic analysis and nature of the binding forces: Thermodynamic parameters viz., enthalpy change $(\Delta \mathrm{H})$, entropy change $(\Delta S)$ and free energy change $(\Delta G)$ of interaction, are essential to interpret the binding mode of bovine serum albumin-drugs complexes, they are analyzed to characterize the acting forces between polydatin and bovine serum albu$\min$. When $\Delta \mathrm{H}$ does not vary significantly in the temperature range studied, both $\Delta \mathrm{H}$ and $\Delta \mathrm{S}$ can be determined from van't Hoff equation (eqn. 3), where $\mathrm{K}$ is the binding constant at the corresponding temperature and $\mathrm{R}$ is the gas constant. $\Delta \mathrm{H}$ and $\Delta \mathrm{S}$ can be calculated from slope and intercept of the regression curve of $\ln \mathrm{K}$ versus $1 / \mathrm{T}$. $\Delta \mathrm{G}$ is further calculated according to eqn. 4.

$$
\begin{aligned}
\ln \mathrm{K} & =-\frac{\Delta \mathrm{H}}{\mathrm{RT}}+\frac{\Delta \mathrm{S}}{\mathrm{R}} \\
\Delta \mathrm{G} & =\Delta \mathrm{H}-\mathrm{T} \Delta \mathrm{S}
\end{aligned}
$$

The values of $\Delta \mathrm{H}, \Delta \mathrm{S}$ and $\Delta \mathrm{G}$ for the interaction of polydatin with bovine serum albumin are summarized in Table3. Generally speaking, the binding forces between drugs and biomolecules mainly include hydrophobic force, electrostatic interaction, van der Waals interaction and hydrogen bond ${ }^{12}$. The negative values of $\Delta \mathrm{G}$ mean that the binding process is spontaneous. Moreover, the negative values of $\Delta \mathrm{H}$ and $\Delta \mathrm{S}$ demonstrate that the binding is mainly enthalpy driven and that hydrogen bond and van der Waals force play major role in the interaction ${ }^{13}$.

\begin{tabular}{ccccc}
\multicolumn{5}{c}{ TABLE-3 } \\
BINDING CONSTANTS OF COMPETITIVE \\
EXPERIMENTS $(\mathrm{T}=302 \mathrm{~K})$
\end{tabular}

Identification of binding site: The globular protein bovine serum albumin consists of three distinct drug-binding sites, which are located within hydrophobic cavities in subdomains IIA and IIIA, respectively. Sudlow et al. ${ }^{14}$ have suggested two distinct binding sites on bovine serum albumin, site I and site II; site I showed affinity for phenylbutazone, warfarin, etc. and site II for flufenamic acid, ibuprofen, etc. Digitoxin binding was found to be independent of sites I and II and binds to site III $^{15}$. To identify the specificity of the polydatin binding, competition experiments were performed with phenylbutazone, flufenamic acid and digitoxin in connection with Sudlow's classification of the binding sites ${ }^{16}$. The binding constants of bovine serum albumin-polydatin system in presence of different site markers are calculated in Table- 3 . Obviously, phenylbutazone or digitoxin only has a little influence on the binding of polydatin with bovine serum albumin, however flufenamic acid has a significant effect on the binding. Hence, the site II is the main binding site for polydatin in bovine serum albumin.

Energy transfer between bovine serum albumin and polydatin: The Förster non-radioactive energy transfer theory is often used to determine the distance between donor and acceptor. According to the theory, the efficiency of energy transfer, $\mathrm{E}$, is defined as eqn. 5:

$$
\mathrm{E}=1-\frac{\mathrm{F}}{\mathrm{F}_{0}}=\frac{\mathrm{R}_{0}^{6}}{\left(\mathrm{R}_{0}^{6}+\mathrm{r}^{6}\right)}
$$

where $\mathrm{F}$ and $\mathrm{F}_{0}$ are the fluorescence intensities of bovine serum albumin in the presence and absence of polydatin, $r$ is the distance between acceptor and donor and $\mathrm{R}_{0}$ is the critical 
distance when the transfer efficiency is $50 \%$. $\mathrm{R}_{0}$ is given by eqn. 6:

$$
\mathrm{R}_{0}^{6}=8.8 \times 10^{-25} \mathrm{k}^{2} \mathrm{~N}^{-4} \Phi \mathrm{J}
$$

where $\mathrm{k}^{2}$ is the spatial orientation factor of the dipole, $\mathrm{N}$ is the refractive index of the medium, $\Phi$ is the fluorescence quantum yield of the donor and $\mathrm{J}$ is the overlap integral of the fluorescence emission spectrum of the donor and the absorption spectrum of the acceptor. $\mathrm{J}$ is given by eqn. 7 :

$$
\mathrm{J}=\frac{\Sigma \mathrm{F}(\lambda) \varepsilon(\lambda) \lambda^{4} \Delta \lambda}{\Sigma \mathrm{F}(\lambda) \Delta \lambda}
$$

where $\lambda$ is wavelength, $F(\lambda)$ is the fluorescence intensity of the donor and $\varepsilon(\lambda)$ is the molar absorption coefficient of the acceptor at $\lambda$. In the present case, $\mathrm{k}^{2}=2 / 3, \mathrm{~N}=1.336$ and $\Phi=$ $0.15^{17,18}$. The overlap of the absorption spectrum of polydatin and the fluorescence emission spectrum of bovine serum albumin is shown in Fig. 5. According to eqns. 5-7. It is calculated that $\mathrm{J}=5.49 \times 10^{-15} \mathrm{~cm}^{3} \mathrm{~L} \mathrm{~mol}^{-1}, \mathrm{R}_{0}=2.31 \mathrm{~nm}, \mathrm{E}=0.085$ and $\mathrm{r}=3.43 \mathrm{~nm}$. The donor-to-acceptor distance is less than 8 $\mathrm{nm}$, which indicates that the energy transfer from bovine serum albumin to polydatin occurs with high possibility ${ }^{19}$. It accords with the condition of Förster non-radioactive energy transfer theory, indicating again the static quenching interaction between bovine serum albumin and polydatin.

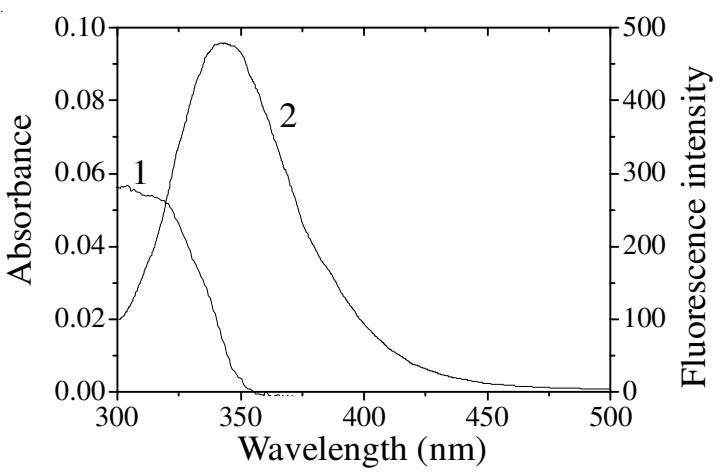

Fig. 5. Overlap of the absorption spectrum of polydatin (1) and the fluorescence spectrum of bovine serum albumin (2). $\mathrm{C}_{\mathrm{BSA}}=\mathrm{C}_{\text {polydatin }}$ $=3.0 \times 10^{-6} \mathrm{~mol} \mathrm{~L}^{-1} ; \mathrm{T}=298 \mathrm{~K}, \mathrm{pH}=7.4$

Conformation investigation: To verify whether the conformation of bovine serum albumin had changed or not, FTIR and its derivative methods were performed. The IR absorbance of the buffer solution was subtracted from the spectrum of the bovine serum albumin solution to obtain the spectrum of bovine serum albumin before binding with polydatin and the absorbance of the polydatin solution was subtracted from the spectrum of the bovine serum albumin-polydatin solution to obtain the spectrum of the bovine serum albumin after binding with polydatin. Then two different spectra were compared and analyzed.

FTIR spectra of proteins exhibit a number of so-called amide bands due to different vibrations of the peptide moiety. Of all the amide bands in bovine serum albumin. FTIR spectra, the amides I (mainly $\mathrm{C}=\mathrm{O}$ stretch) and amide II (C-N stretch coupled with $\mathrm{N}-\mathrm{H}$ bending mode) bands both have a relationship with the secondary structure of the protein and amide I band is more sensitive to the change of the protein secondary structure than amide II band ${ }^{20}$. The amide I band gives rise to infrared bands in the region of $1700-1600 \mathrm{~cm}^{-1}$ and amide II band in the region of $1600-1500 \mathrm{~cm}^{-1}$. The FTIR difference spectra of bovine serum albumin before and after interaction with polydatin in Tris- $\mathrm{HCl}$ buffer are shown in Fig. 6. Compared with the spectrum of bovine serum albumin before interaction, the peak positions of amide I and II bands in the spectrum of bovine serum albumin after interaction have small shift suggesting the conformation of bovine serum albumin has been affected by the addition of polydatin.

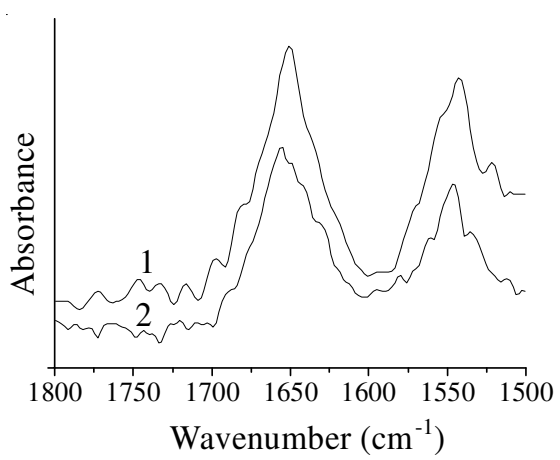

Fig. 6. FTIR difference spectra of bovine serum albumin in Tris-HCl buffer solution. (1) bovine serum albumin before binding $\left(\mathrm{C}_{\mathrm{BSA}}=1.0 \times\right.$ $\left.10^{-4} \mathrm{~mol} \mathrm{~L}^{-1}\right)$; (2) bovine serum albumin after binding $\left(\mathrm{C}_{\mathrm{BSA}}=1.0 \times\right.$ $\left.10^{-4} \mathrm{~mol} \mathrm{~L}^{-1}, \mathrm{C}_{\text {polydatin }}=2.0 \times 10^{-4} \mathrm{~mol} \mathrm{~L}^{-1}\right)$

Before the estimation of percentage content of each secondary structure, the component bands should be assigned. According to the literature ${ }^{21,22}$, the spectral ranges of 1640$1610 \mathrm{~cm}^{-1}$ is generally assigned to $\beta$-sheet, $1650-1640 \mathrm{~cm}^{-1}$ to random coil, $1650-1659 \mathrm{~cm}^{-1}$ to $\alpha$-helical and $1700-1660 \mathrm{~cm}^{-1}$ to $\beta$-turn structure in the amide I band. To quantitatively analyze the protein secondary structure, the second derivative resolution enhancement and infrared self-deconvolution are applied to estimate the number and position of component bands in the amide I; then curve fitting procedures are used to fit the original protein spectrum. The percentage of each secondary structure of bovine serum albumin is calculated based on the integrated areas of the component bands in amide I and the results are shown in Fig. 7. The results show that before and after interaction with polydatin, the major secondary structures of bovine serum albumin have changed: $\alpha$-helical structure increases from $53-59 \%, \beta$-sheet increases from $22-26 \%$ and $\beta$-turn structures decreases from $25-15 \%$, respectively.

\section{Conclusion}

Interaction mechanism of polydatin with bovine serum albumin has been investigated by fluorescence spectroscopy combined with UV-visible and FTIR spectrophotometric techniques. The results show that polydatin interacts with bovine serum albumin through a static quenching mechanism and polydatin most likely bound to the hydrophobic pocket located at site II in subdomain IIIA. The thermodynamic analysis also suggested that the interaction is spontaneous and driven by enthalpy and the main interaction forces are hydrogen bond and van der Waals force. In addition, the conformation of bovine serum albumin is changed after bonding with polydatin and the binding increases the $\alpha$-helix and $\beta$-sheet structure at the cost of a loss in the $\beta$-turn structure. 

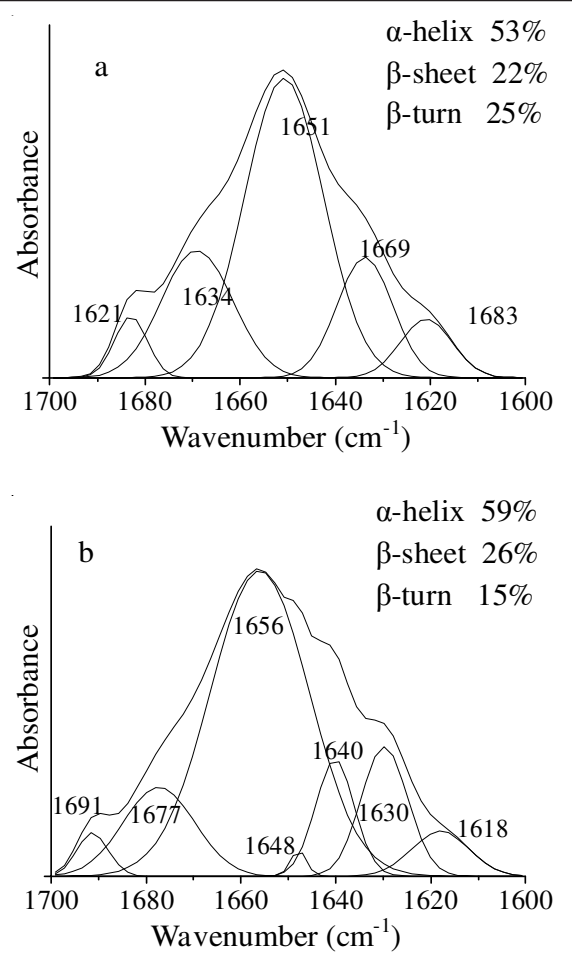

Fig. 7. Curve-fitted amide I region for FTIR difference spectra of bovine serum albumin. (a) bovine serum albumin before binding $\left(\mathrm{C}_{\mathrm{BSA}}=1.0\right.$ $\left.\times 10^{-4} \mathrm{~mol} \mathrm{~L}^{-1}\right)$; (b) bovine serum albumin after binding $\left(\mathrm{C}_{\mathrm{BSA}}=1.0\right.$ $\times 10^{-4} \mathrm{~mol} \mathrm{~L}^{-1}, \mathrm{C}_{\text {polydatin }}=2.0 \times 10^{-4} \mathrm{~mol} \mathrm{~L}^{-1}$ )

\section{ACKNOWLEDGEMENTS}

The authors gratefully acknowledged the financial support of this study by the special fund for Basic Scientific Research of Central Colleges ofChang'an University (CHD2012JC093) and the National Natural Science Foundation of China (Grant No. 20975081).

\section{REFERENCES}

1. V.M. Rosenoer, M. Oratz and M.A. Rothschild, Albumin: Structure, Function and Uses, Pergamon Press, Oxford, pp. 27-51 (1977).

2. R.E. Olson and D.D. Christ, Ann. Rep. Med. Chem., 31, 327 (1996).

3. D.C. Carter, B. Chang, J.X. Ho, K. Keeling and Z. Krishnasami, Eur. J. Biochem., 226, 1049 (1994).

4. P. Chen, Y. Yun, B. He, S. Ma and Z. Shen, Afr. J. Biotechnol., 10, 14177 (2011).

5. C. Sheng, Y. Yu, K. Zhao, W. Qin and C. Wang, J. Surg. Res., 168, 103 (2011).

6. J. Du, L. Sun, W. Xing, K. Huang, M. Jia, J. Wu, H. Zhang and L. Qin, Phytomedicine, 16, 652 (2009).

7. K. Zhao, C. Jin, X. Huang, J. Liu, W. Yan, Q. Huang and W. Kan, Clin. Hemorheol. Microcirc., 29, 211 (2003).

8. B.H.M. Hussein, J. Lumin., 131, 900 (2011).

9. J.R. Lakowicz, Principles of Fluorescence Spectroscopy, Plenum, New York, edn. 2, pp. 239-240 (1999).

10. T.G. Dewey, Biophysical and Biochemical Aspects of Fluorescence Spectroscopy, Plenum Press, New York, pp. 1-41 (1991).

11. A. Belatik, S. Hotchandani, J. Bariyanga and H.A. Tajmir-Riahi, Eur. J. Med. Chem., 48, 114 (2012).

12. P. Bourassa, I. Hasni and H.A. Tajmir-Riahi, Food Chem., 129, 1148 (2011).

13. D.P. Ross and S. Subramanian, Biochemistry, 20, 3096 (1981).

14. G. Sudlow, D.J. Birkett and D.N. Wade, Mol. Pharmacol., 12, 1052 (1976).

15. I. Sjoholm, B. Ekman, A. Kober, I.L. Pahlman, B. Seiving and T. Sjodin, Mol. Pharmacol., 16, 767 (1979).

16. Q.L. Zhang, Y.N. Ni and S. Kokot, J. Pharm. Biomed., Anal., 52, 280 (2010).

17. H. Xu, Q.W. Liu and Y.Q. Wen, Spectrochim. Acta A, 71, 984 (2008).

18. P.B. Kandagal, S. Ashoka, J. Seetharamappa, V. Vani and S.M.T. Shaikh, J. Photochem. Photobiol. A, 179, 161 (2006).

19. S. Weiss, Science, 283, 1676 (1999).

20. J.W. Brauner, C.R. Flach and R. Mendelsohn, J. Am. Chem. Soc., 127, 100 (2005).

21. W.K. Surewicz, H.H. Mantsch and D. Chapman, Biochemistry, 32, 389 (1993).

22. Y. Li, W. He, H. Liu, X. Yao and Z. Hu, J. Mol. Struct., 831, 144 (2007). 